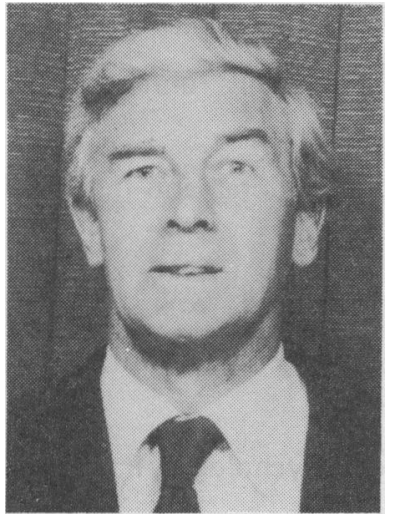

D. H. Williams

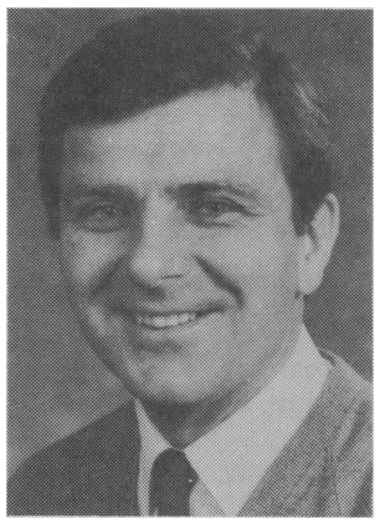

C. Williams

\title{
CARDIOVASCULAR AND METABOLIC RESPONSES OF TRAINED AND UNTRAINED MIDDLE-AGED MEN TO A GRADED TREADMILL WALKING TEST
}

\author{
D. H. WILLIAMS, BA, MA, MSc, DLC and C. WILLIAMS, BSc, MSc, PhD \\ Department of Physical Education and Sports Science, University of Technology, Loughborough, Leics. LE11 $3 T U$
}

\begin{abstract}
A treadmill walking test was developed in order to provide a suitable method of assessing the fitness levels of sedentary middle-aged men (mean age, $\mathbf{4 4 . 3}$ yrs) at submaximal intensity. The incremental stages of the test enabled subjects to terminate the workload whenever undue discomfort was experienced. The test procedure was used in a preliminary experiment to compare the cardiovascular and metabolic responses of trained and untrained middle-aged men to exercise. Heart rate responses to the test were significantly higher $(p<0.01)$ in the untrained, compared with the trained, men as were the post-exercise blood lactic acid concentrations ( $p<0.01$ ), Respiratory Exchange Ratios $(p<0.01)$, Ventilatory Equivalents $(p<0.05)$ and Rate of Perceived Exertion $(p<0.01)$. However, there were no differences in the oxygen cost of walking between the two groups.
\end{abstract}

Key words: Walking test, Middle-aged men, Lactates, Heart rates, Oxygen uptake, Perceived exertion.

\section{INTRODUCTION}

The maximum oxygen uptake $\left(\mathrm{VO}_{2} \max \right)$ of an individual reflects his cardio-respiratory capacity for oxygen transport (Taylor et al, 1955; Rowell, 1974; Saltin, 1980) and it has been suggested that it is the single most important indicator of endurance fitness (Shephard et al, 1968). The highest $\mathrm{VO}_{2} \max$ values. have been recorded for young endurance trained athletes during uphill treadmill running (Saltin and Åstrand, 1967). However it is neither desirable nor responsible to ask middle-aged people to undertake a $\mathrm{VO}_{2}$ max test when their habitual exercise levels are recondite or sedentary. Therefore a submaximal treadmill walking test was devised in order to serve as the first level of a two level system for examining an individual's physiological responses to exercise. Only when their responses to the walking test are comparable with those of trained individuals would formerly untrained individuals progress to the second level of examination, namely a $\mathrm{VO}_{2}$ max test involving uphill running.

In exercise tests which attempt to cater for sedentary and active individuals alike, the test protocols involve a progression from a slow walk to jogging or running on ever steeper grades until fatigue or attendant symptoms of stress intervene (Bruce et al, 1963; Bruce and McDonough, 1969; Froelicher et al, 1974). All these comprehensive tests are characterised by slow walking speeds and steep inclinations early in the test, a combination which was found, during a preliminary investigation, to be unpopular with both trained and untrained subjects. Therefore the test used in the present study was one in which the walking speed was held constant and only the gradient was varied because increases in gradient were found to be less intimidating than changes in treadmill speed. Therefore the purpose of the present 
study was to determine whether or not the exercise challenge presented by the walking test was sufficient to discriminate between the physiological responses of trained and untrained middle-aged men to this type of submaximal exercise.

\section{METHODS}

Fifteen middle-aged men whose average age is shown in Table I, were selected from a volunteer group of twentytwo males, age range 22-61 years. Five of the subjects were untrained while ten of them were trained. The level of habitual activity of the former was negligible, ranging from the purely sedentary to once-a-week golf. All trained subjects were extremely active at least three times a week, some on a daily basis. They participated in regular, recreational or competitive regimes related to their chosen sports or by carrying out specific programmes designed to improve, or maintain, a high level of fitness. Sports were as widely diverse as squash, training for the decathlon, sprint and endurance swimming and marathon running.

\section{TABLE I}

Physical characteristics of trained and untrained males (Mean \pm S.D. and range).

$\begin{array}{lcc}\text { Variable } & \text { Trained } & \text { Untrained } \\ n & .10 & 5 \\ \text { Age }(y r s) & 43.7 \pm 3.8 & 45.4 \pm 2.7 \\ & (39-48) & (42-49) \\ \text { Height }(\mathrm{cm}) & 174.1 \pm 7.3 & 176.6 \pm 6.5 \\ & (161.5-182.1) & (165.5-182.5) \\ \text { Weight }(\mathrm{kg}) & 68.9 \pm 9.1 & 74.5 \pm 7.4 \\ & (54.3-81.8) & (62.3-80)\end{array}$

Training régimes of the 10 subjects "in training":-

3 subjects training for the marathon:

Subject 1: trained twice a day, covering a total of 10 miles.

Subject 2: $\quad$ ran 10 miles, cycled 20 miles, swam 1 mile per day.

Subject 3: ran once per day, covering 7 miles.

2 Veteran Decathletes preparing for the Veterans' National Decathlon Championships:

Subject 1: trained once every other day - included skill training, sprint repetitions and middle and long distance running.

Subject 2: trained every day on skill, sprint and middle-distance work.

1 National Athletics Coach: ran 60 miles per week.

1 Charnwood A.C. athlete: ran 10 miles per week, walked 10 miles per week (also competed as a race walker).
1 Veteran Swimmer: in daily training for the National Veterans' Back Crawl Swimming Championships - an all-the-year round swimmer.

1 subject training for a Half Marathon: swam 500 yds., cycled 5 miles, ran 5 miles each day.

1 subject training for Squash tournaments: daily Squash.

The test itself lasted ten minutes and comprised five grades at $5 \%, 10 \%, 12.5 \%, 15 \%$ and $17.5 \%$ each continuing for two minutes, maintained at a speed of $5.6 \mathrm{~km} . \mathrm{hr}^{-1}$ (3.5 mph) throughout. Prior to testing, the height and weight of each subject was taken; he was then rested for ten minutes during which time resting blood pressure was measured using an automatic sphygmomanometer (Bonn, Model D) and resting heart rate using a digital heart rate monitor (Woodway Ltd.). A two minute warm-up was obligatory at the test speed with no elevation of the treadmill.

- The heart rate was monitored continuously during the test and for four minutes of recovery. The test was terminated earlier than 10 minutes if the subject's heart rate reached a predicted maximum value: $H R$ max $=$ 210 -(age x 0.65), (Åstrand, 1960). Subjective responses were followed using Borg's Rate of Perceived Exertion (Borg, 1962) which is a fifteen point scale ranging from 6 to 20: 6 represented complete rest, 20 complete exhaustion. The subjects were able to terminate the test voluntarily at any stage when it became distressing.

During the test the subject breathed through a low resistance valve (Jakeman and Davies, 1979) into a twelve litre mixing chamber which was, in turn, connected to a 600 litre Tissot spirometer (W. Collins Ltd., USA). The composition of the expired air in the mixing chamber was analysed by a respiratory mass Spectrometer (Centronic Type 007, Centronics Ltd.). A high resolution flat bed pen recorder (Rikadenki Ltd.) was connected to both the mass Spectrometer and to the Tissot Spirometer enabling pulmonary ventilation, percentages of oxygen and carbon dioxide and frequency of breathing to be recorded every thirty seconds.

Before, and immediately after the test, blood samples were obtained from a finger-prick of the subject's prewarmed hand. Haemoglobin concentrations were then determined by the standard cyanomethoglobin method and deproteinized blood samples, frozen in aliquots at $-20^{\circ} \mathrm{C}$, were later analysed for lactic acid by a modified spectrophotometric method (Olsen, 1971). Statistical analysis was calculated using the Student's ' $t$ ' test.

\section{RESULTS}

There were no significant differences in age, height 
and weight between the two groups (Table 1). All trained subjects completed the test, whilst two of the untrained group stopped voluntarily after the penultimate workload.

Blood pressure showed little change within each group, before and after exercise. Maximum recorded heart rates were significantly different $(p<0.01)$ (Table II) at the end of the final workload (Fig. 1) and after four minutes of recovery. There were also significant differences between the Rates of Perceived Exertion of the two groups $(p<0.01)$.

\section{TABLE II}

Physiological responses of the two groups (Mean \pm S.D.).

\begin{tabular}{|c|c|c|c|c|}
\hline \multirow{2}{*}{$\begin{array}{l}\text { Variable } \\
\text { Blood Pressure }(\mathrm{mm} . \mathrm{Hg})\end{array}$} & \multicolumn{2}{|c|}{ Trained } & \multicolumn{2}{|c|}{ Untrained } \\
\hline & & & & \\
\hline \multicolumn{5}{|l|}{ Pre-exercise:- } \\
\hline Systolic & 137 & \pm 16.1 & 130 & \pm 9.3 \\
\hline Diastolic & 85 & \pm 11.4 & 77 & \pm 5.9 \\
\hline \multicolumn{5}{|l|}{ Post-exercise:- } \\
\hline Systolic & 135 & \pm 12.7 & 128 & \pm 8.9 \\
\hline Diastolic & 85 & \pm 6.9 & 75 & \pm 3.9 \\
\hline \multicolumn{5}{|l|}{ Haemoglobin (g. $\mathrm{dl}^{-1}$ ) } \\
\hline Pre-exercise & 14.8 & \pm 1.5 & 14.5 & \pm 1.3 \\
\hline Post-exercise & 15.0 & \pm 0.9 & 15.7 & \pm 1.9 \\
\hline \multicolumn{5}{|l|}{ Lactate conc. (mM) } \\
\hline Pre-exercise & 1.52 & \pm 0.24 & 1.27 & \pm 0.47 \\
\hline Post-exercise (1) & 3.35 & \pm 1.65 & 7.59 & \pm 2.1 \\
\hline Post-exercise (2) & 3.40 & \pm 1.48 & 7.56 & \pm 2.04 \\
\hline$V_{E F F}$ (Vent. Equivalent) & 23.6 & \pm 3.8 & 28.9 & \pm 5.4 \\
\hline R (Resp. Exch. Ratio) & 1.03 & \pm 0.1 & 1.22 & \pm 0.16 \\
\hline \multicolumn{5}{|l|}{ Heart rates (beats $\min ^{-1}$ ) } \\
\hline Rest & 55.4 & \pm 8.3 & 68.8 & \pm 8.1 \\
\hline Max. recorded & 156.8 & \pm 10.1 & 183.2 & \pm 7.5 \\
\hline Recovery (4 mins) & 75.9 & \pm 12.9 & 102.2 & \pm 8.8 \\
\hline Predicted HR max & 181.7 & \pm 2.5 & 180.5 & \pm 1.7 \\
\hline \multicolumn{5}{|l|}{ RPE } \\
\hline (Rate Perceived Ex & 12.6 & \pm 2.4 & 17.2 & \pm 1.5 \\
\hline
\end{tabular}

Haemoglobin concentrations were maintained at a normal level throughout the test period and there were no significant differences either between groups or before and after exercise. While there was no difference between the pre-exercise blood lactate concentrations of the two groups, significant differences $(p<0.01)$ were found between the groups two to three minutes after exercise (Fig. 2).

Similarly, $R$ values were significantly $(p<0.01)$ higher in the untrained group and this difference was also reflected in the ventilatory equivalents between the two groups (Table II). There was, however, no

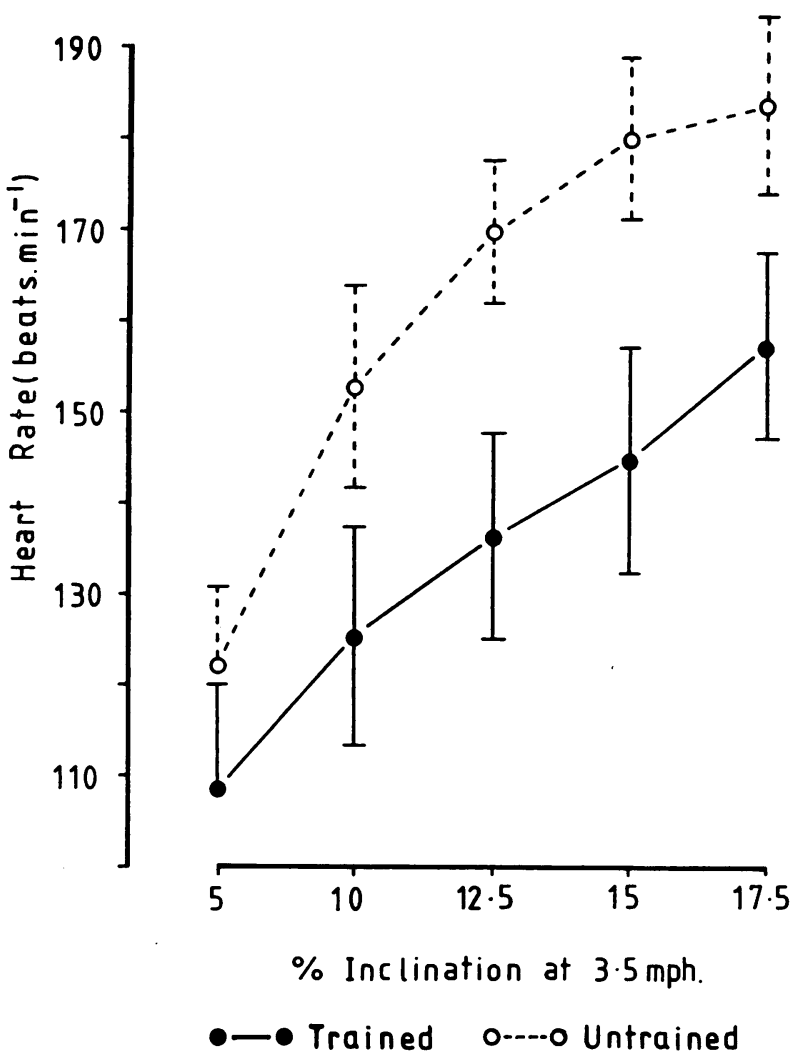

Fig. 1: The changes in heart-rates (mean $\pm S D$ ) of trained and untrained middle-aged men during the uphill treadmill walking test.

significant difference in oxygen uptake between the groups for each of the five workloads (Fig. 3).

\section{DISCUSSION}

The test devised by Bruce (1972) lasted twelve minutes, the multi-stages, each of three minutes, consisting of: $1.7 \mathrm{mph}$ at $10 \%$ grade, $2.5 \mathrm{mph}$ at $12 \%, 3.4 \mathrm{mph}$ at $14 \%$ and $4.2 \mathrm{mph}$ at $16 \%$, the choice of walking or running being left to the subject during the final stage. As can be seen, the test is characterised by a narrow range of high inclinations initially attempted at a very low speed and concluded at a high speed. It was felt that, in the present context, the stages were insufficiently progressive in gradient and placed the untrained subject at a mechanical disadvantage when he was left with a choice between a fast walk and a run during the final stage. The aim of the present test was therefore, to employ a procedure which was reasonably taxing but not unique to the inexperienced subject. The more common exercise test mode favours the trained individual who finds work on bicycle ergometer and treadmill often familiar through his own form of 


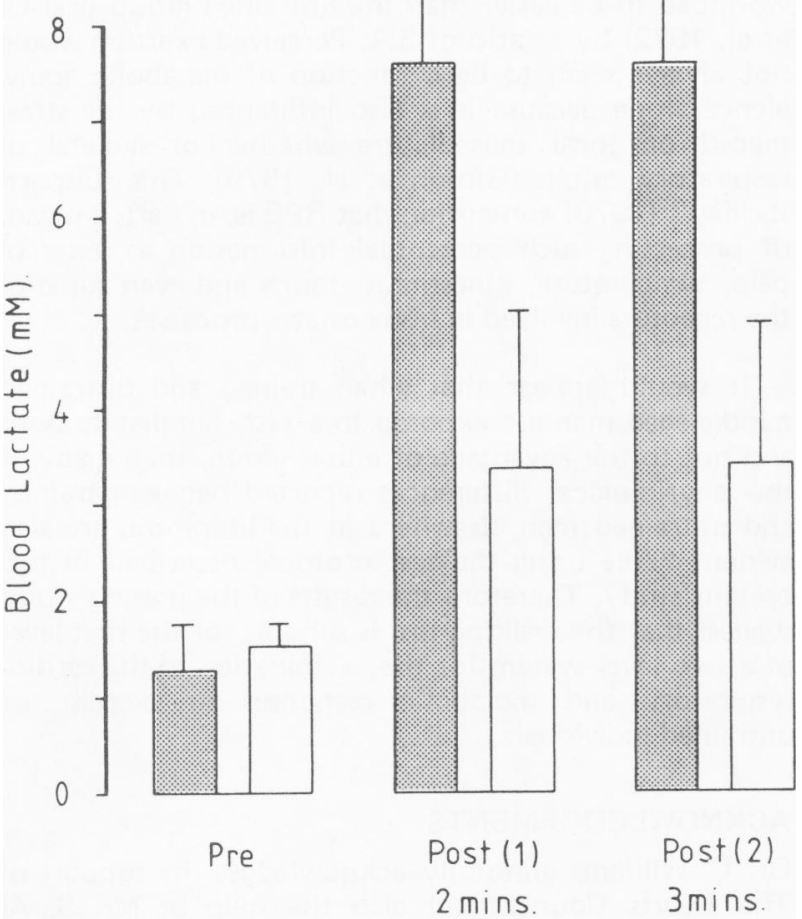

Trained

\section{Untrained}

Fig. 2: Blood lactate concentrations (mean $\pm S D$ ) of trained and untrained middle-aged men before and after the treadmill walking test.

athletic pursuit. Thus, by setting the treadmill at a constant walking speed and providing a progressive increase in inclinations, an exercise pattern was established which was not unfamiliar to the untrained individual and yet allowed the trained to reveal some of the training-induced physiological advantages.

The mean haemoglobin values for both groups were essentially the same (Table II) and fell within the normal range of values for adult males i.e. 13.8-15.9 g.d $\Gamma^{1}$ (Brotherhood et al, 1975). Haemoglobin concentrations did not increase during exercise and so the walking test did not produce any detectable haemoconcentration. There was no significant difference between the oxygen consumption during exercise of the trained and untrained individuals and this result is consistent with the findings of other authors (Varnauskas et al, 1966; Saltin et al, 1968; Clausen et al, 1969; Saltin et al, 1971). The absence of a difference in the oxygen consumption between the two groups during the sub-

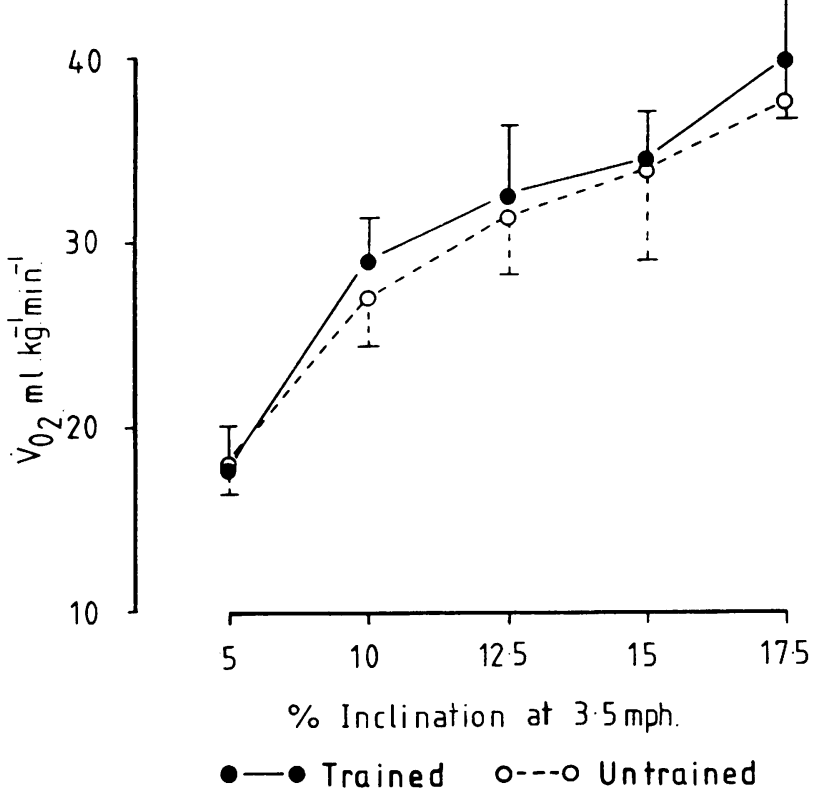

Fig. 3: The oxygen consumption (mean $\pm S D$ ) of trained and untrained middle-aged men during the uphill treadmill walking test.

maximal exercise indicates that both the trained and the untrained individuals were equally skilled at the task of uphill walking. This result indicated that the choice of test protocol was appropriate in that neither the trained nor the untrained individuals were able to claim any advantages while performing this test.

The higher blood lactate concentrations of the untrained group after exercise (Fig. 2) reflects a larger contribution of carbohydrate to energy metabolism and this is confirmed by the higher $R$ values of the untrained group compared with those of the trained group. In contrast the lower blood lactate concentrations of the trained group indicates that they were able to complete the walking test almost entirely at the expense of aerobic metabolism. The lower rate of blood lactate accumulation during exercise of increasing intensity is a characteristic of endurance trained individuals and is mainly due to the increased oxidative capacity of their skeletal muscles (Saltin and Karlsson, 1971; Gollnick et al, 1973). As a consequence of an increased aerobic capacity, the skeletal muscles of trained individuals are able to utilise a greater proportion of fat for energy metabolism and so conserve their limited carbohydrate stores (Henriksson, 1977). In addition the increased oxidative capacity of skeletal muscle appears to be largely responsible for the reduced cardio-respiratory responses to submaximal exercise after training (Clausen, 1977). The lower heart-rate of trained individuals during sub-maximal exercise is attributed mainly to their 
greater stroke volumes than those of untrained individuals (Saltin and Rowell, 1980). However there is also evidence to suggest that trained muscles are able to extract more of the oxygen offered to them and can therefore function with a reduced blood flow during submaximal exercise (Clausen et al, 1969). This in turn may lead to a better matching of cardiac output and oxygen consumption with the result that lower heart rates occur during submaximal exercise after training (Andrew et al, 1966; Clausen et al, 1973).

It is very difficult, however, to assess how much of the increased heart-rate response to submaximal exercise by untrained individuals is due to the lack of the peripheral adaptations described above and how much is the result of psychogenic recruitment of the sympathetic nervous system in response to a physical challenge. Familiarisation with the exercise task, by repeated exposure, does not provide the complete answer to the problem but it does raise the question about where familiarisation ends and training begins (Davies et al, 1970). In the present study the higher heart-rates of the untrained individuals were recorded while performing an exercise task which was familiar to both the untrained and trained groups. Therefore the higher heart-rates were mainly due to the differences in "training status" per se, rather than to differences in the degree of psychogenic stress present during the test.

In contrast to the observations reported in the literature that the correlation between Rate of Perceived Exertion and heart rate fall between 0.75 and 0.90 (Borg, 1962; Borg et al, 1967; Frankenhaeuser et al, 1969; Skinner et al, 1970), the findings of this study showed only modest correlations of $\mathbf{0 . 6 1}$ for the trained group, $\mathbf{0 . 6 5}$ for the untrained. This could be accounted for by the inexperience of both groups in using the Borg Scale. The trained subjects perceived a submaximal workload to be easier than the untrained group (Bar-Or et al, 1972) by a ratio of 3:1. Perceived exertion would not always seem to be a function of metabolic equivalence alone because it is also influenced by the stress placed on local musculature whether of skeletal or respiratory origin (Gibson et al, 1979). This supports Bartley's (1970) contention that RPE is, in part, a means of processing such perceptual information as sense of pain, temperature, kinesthesis, touch and even some of the receptors involved in homeostatic processes.

It would appear that when trained and untrained middle-aged men are exposed to a test, familiar to both and not to the advantage of either group, then many of the physiological differences reported between trained and untrained men elsewhere in the literature, are also evident while using the test protocol described in this present study. Therefore the results of the present study suggest that the walking test is suitable for the first level of a two level system for the examination of the cardiorespiratory and metabolic responses to exercise of untrained individuals.

\section{ACKNOWLEDGEMENTS}

Dr. C. Williams gratefully acknowledges the support of The Sports Council and also the help of Mr. S. A. Wootton and Mr. M. R. Shorten in establishing the semi-automated system for the analysis of samples of expired air.

\section{REFERENCES}

Andrew, G. M., Guzman, C. A. and Becklake, M. R., 1966 "Effect of athletic training on exercise cardiac output". J.Appl.Physiol. 21: 603-608.

Åstrand, I., 1960 "Aerobic work capacity in men and women with special reference to age". Acta physiol.scand. 49: Suppl. 169.

Bar-Or, O., Skinner, J., Buskirk, E. and Borg, G., 1972 "Physiological and perceptual indicators of physical stress in 41 to 61 year-old men who vary in conditioning level and in body fatness". Med.Sci.Sports 4: 96-100.

Bartley, S. H., 1970 "The homeostatic and comfort perceptual systems". Jour.Psychol. 75: 157-162.

Borg, G. A. V., 1962 "Physical performance and perceived exertion". Thesis, Lund.

Borg, G. and Linderholm, H., 1967 "Perceived exertion and pulse rate during graded exercise in various age groups". Acta Med.Scand.Suppl. 472: 194-206.

Brotherhood, J., Borozovic, B. and Pugh, L., 1975 "Haematological status of middle- and long-distance runners". Clin.Sc.Mol.Med. Vol. 48: 139-145.

Bruce, R. A., Blackman, J. R., Jones, J. W. and Strait, G., 1963 “Exercise testing in adult normal subjects and cardiac patients". Pediatrics 32: 742-755. 
Bruce, R. A. and McDonough, J. R., 1969 "Stress testing in screening for cardiovascular disease". Bull.N.Y.Acad.Med. 45: $1288-1305$.

Bruce, R. A., 1972 "Exercise testing and training of apparently healthy individuals: a handbook for physicians". Committee on Exercise, American Heart Assoc.

Clausen, J. P., Larsen, O. A. and Trap-Jensen, J., 1969 "Physical training in the management of coronary artery disease". Circulation 40: 143-154.

Clausen, J. P., Klausen, K., Rasmussen, B. and Trap-Jensen, J., 1973 “Central and peripheral circulatory changes after training of the arms or legs". Am.J.Physiol. 225: 675-682.

Clausen, J. P., 1977 "Effect of physical training on cardiovascular adjustments to exercise in man". Physiol.Rev. 57: 779-815.

Davies, C. T. M., Tuxworth, W. and Young, J. M., 1970 "The physiological effects of repeated exercise". Clin.Sci. 39: 247-258.

Frankenhaeuser, M., Post, B., Nordheden, B. and Sjoeberg, H., 1969 "Physiological and subjective reactions to different workloads". Percept.Mot.Skills 28: 343-349.

Froelicher, V. F., Brammel, H., Davis, G., Noguera, I., Stewart, A. and Lancaster, M. C., 1974 "A comparison of three maximum treadmill exercise protocols". J.Appl.Physiol. 36: 720-725.

Gibson, T. M., Harrison, M. H. and Wellicombe, R. M., 1979 "An evaluation of a treadmill work test". Brit.Jour.Sports Med. 13: 6-11.

Gollnick, P. D., Armstrong, R. B., Saltin, B., Saubert, C. W., Sembrowich, W. L. and Shepherd, R. E., 1973 “Effect of training on enzyme activity and fibre composition of human skeletal muscle". J.Appl.Physiol. 34: 107-111.

Henriksson, J., 1977 "Training induced adaptation of skeletal muscle and metabolism during submaximal exercise". J.Physiol. 270: 661-675.

Jakeman, P. and Davies, B., 1979 "The characteristics of a low resistance breathing valve designed for the measurement of high aerobic capacity". Brit.Jour.Sports Med. 13: 81-83.

Olsen, C., 1971 "An enzymatic fluorimetric micromethod for the determination of acetoacetate, B-hydroxybutyrate, pyruvate and lactate". Clin.Chim.Acta 33: 293-300.

Rowell, L. B., 1974 “Human cardiovascular adjustments to exercise and thermal stress”. Physiol. Rev. 54: 75-159.

Saltin, B. and Åstrand, P. O., 1967 "Maximal oxygen uptake in athletes”. J.Appl.Physiol. 23: 353-358.

Saltin, B., Blomqvist, G., Mitchell, J., Johnson, R., Jnr., Wildenthal, K. and Chapman, C., 1968 "Response to exercise after bed rest and after training". Circulation 38, Suppl. 7: 1-78.

Saltin, B. and Karlsson, J., 1971. In: "Muscle Metabolism During Exercise". Pernow and Saltin (Eds.), Plenum, New York, pp. 395-399.

Saltin, B. and Rowell, L. B., 1980 "Functional adaptations to physical activity and inactivity". Fed.Proc. 39: 15061513.

Shephard, R. J., Allen, C., Benade, A. J. S., Davies, C. T. M., Di Prampero, P. E., Hedman, R., Merriman, J. E., Myhre, $K$. and Simmons, R., 1968 "The maximal oxygen uptake. An international reference standard of cardio-respiratory fitness". Bull.WHO 38: 757-764.

Skinner, J. S., Borg, G. and Buskirk, E., 1970 "Physiological and perceptual reactions to exertion of young men differing in activity and body size". In: Exercise and Fitness. Franks, B. D. (Ed.), Chicago: Athletic Institute. 
Taylor, H. R., Buskirk, E. R. and Henschell, A., 1955 "Maximum oxygen intake as an objective measure of cardiorespiratory performance". J.Appl.Physiol. 8: 73-80.

Varnauskas, E., Bergman, H., Houk, P. and Björntorp, P., 1966 "Haemodynamic effect of physical training in coronary patients". Lancet 2: 8-12.

\section{BOOK REVIEW}

Title:

Authors:

Publishers:

\section{MODERN PRINCIPLES OF ATHLETIC TRAINING}

Carl E. Klafs and Daniel D. Arnheim. 5th Edition

C. V. Mosby

Price $\mathbf{£ 1 5 . 5 0}$

\section{6 pages}

This is an interesting volume assembled by two physical educationists in four main sections.

Part I, "The Field of Athletic Training" generally reviews the background to physical education and training, the role of the trainer and his responsibilities and relevant facilities. While much of the detail is relevant mainly to American practice, this is generally the best section of the book with clear definitions of job skills and the basic preparation of the sportsman in training. There are clear guidelines for a code of ethics, based on the American National Athletic Trainers Association's code which defines the limits of competence and responsibility of the trainer and could well act as the model for such work. The lavish facilities indicated in the relevant section would embarrass many British hospitals and can add a certain perspective to our professional ambitions!

Part II, on the general principles of athletic training is patchy. There is much sound description and information. The statement that American football accounts for some 40,000 knee operations annually emphasises the need for more progressive approaches to diagnosis and management. Unfortunately, a number of dubious statements and incorrect facts may misinform the unwary; for instance, I thought that it had been well established that spinal posture was not a direct result of athletic movement and a fundamental misunderstanding is implied in the statement that "most over-use injuries occur at this moment of impact". The description of cardiac response to training is erroneous, as is the interpretation of international doping regulations before competition.

Statements that negative ionisation causes considerable euphoria and that it is generally accepted that ions affect our moods, circulation and respiration may give rise to some scepticism. A certain mental confusion of the chicken and egg variety is well illustrated by "the type of athletic activity in which the sportswoman participates seems to affect her adiposity. For example, runners are much leaner than women who compete in the weight events." Similarly, statements like "menarche, like menstruation, is regular in its irregularity" are not very scientific in a reference book, nor is the simplistic summary of "dysmenorrhea".

As expected, the chapters on conditioning, exercise regimes, with excellent illustrations, and protective and preventive factors in sports trauma are the best. However, whenever the subject becomes clinically orientated the reliability slides so that the last sections of the book do not add a great deal to knowledge. The reviewer was intrigued by figure 21.3 showing relief of a condition described as testicular spasm, technique 1, by highly attractive young therapist flexing the knee of the lying subject. The text really should have made it clear whether one should raise the ipsilateral or contralateral limb.

As with so many volumes in this field, the idea is good, the presentation excellent, the need very great, but the contents a distinct let down - inconsistent in their consistency. As with too many texts, brevity and clarity are too often missing and a higher degree of editorial stringency is required in checking facts. Students take texts as gospel and wrong facts render a great disservice regardless of how many good features a book may have. I have learnt a great deal from this book but it should be read with scepticism until subsequent editions put its factual content beyond reproach.

P. N. Sperryn, FRCP (Glasg), DPhysiMed 